$16^{\text {th }}$ International Conference on

AEROSPACE SCIENCES \& AVIATION TECHNOLOGY,

ASAT - 16 - May 26 - 28, 2015, E-Mail: asat@mtc.edu.eg

Military Technical College, Kobry Elkobbah, Cairo, Egypt

Tel : +(202) 24025292 - 24036138, Fax: +(202) 22621908

\title{
Blade Optimization Approach for a Vertical Wind Turbine
}

\author{
Ahmed Ali Geneid*, Ahmed Badawy ${ }^{\dagger}$, and Mostafa R.A. Atia ${ }^{\dagger}$
}

\begin{abstract}
Harvesting electrical power from wind energy is a feasible solution for the issue of abundance energy. Blade is the wind turbines performance key. The research considered the design and optimization issue of blade's structure made from composite material. Genetic algorithm used as an optimization tool for defining different parameters in the blade fibre and matrix materials, fibre orientations, layer thickness, and number of layers for blade crosssection. Building an efficient genetic algorithm requires a good representation to the phenomenon through an appropriate definition of the fitness function. The presented approach aim to optimize the blade deign against different loads such as aerodynamic, inertia, and operating couples. Material model predicate all properties in principal directions. Force model analyze all external force-couple system. Stress and failure model evaluate all stress condition then check their values against material strength. Failure criterion determines whether the proposed model is safe or not. All these parameters embedded into single fitness function to decide whether this model would replace one of the preceding generation or not. New design parameters produced through crossover, mutation, and replacement processes until the algorithm converges. The results form presented approach is a design benchmark for blade material design and selection process.
\end{abstract}

Keywords: wind turbine blade, composite materials, genetic algorithm.

\section{Introduction}

The vertical wind turbines blade is designed to support air and centrifugal loads. Hence, mathematical equations are derived to describe shape parameters, stress analysis, and failure analysis. After that, a representation for the mathematical model in the form of genetic algorithm, while handling the mixed integer parameter issue in the programming. Consequently, the fitness evaluation model overcomes this problem by using index material selection and continues parameters as dimensions and number of layers.

Optimization decision parameters have the behaviour of integer programming. Parameters include index for selected reinforcement material, matrix material, orientation of reinforcement, number of layers, volume fraction, and width of core box. Genetic algorithm generates random values for those parameters, and then they fed into evaluation model for the objective function that includes the mechanical model evaluating failure conditions. The fitness value used in reproducing new offspring, first by selecting fitter designs, then crossover and mutates the selected designs; finally, a new population is then created. Algorithm is repeated until changes in fitness value stall.

\footnotetext{
* Graduate Student in the Arab Academy for Science, Technology and Maritime Transport, TA in the Canadian International College, Cairo, Egypt, ageneid@gmail.com

$\dagger$ Egyptian Armed Forces, Egypt, ahmed.badawy@lycos.com

* Associate Professor in the Arab Academy for Science, Technology and Maritime Transport, mrostom1@yahoo.com
} 
Ladson and Brooks in 1975 started the first step to compute and draw the NACA cross section using computer based program [1]. They introduced a systematic equations to relate the shape with $x$ and $y$-axis. In addition to, other shape parameters were related too such as camber location, maximum thickness of airfoil, and there relation to chord length. 2013 Manikandan and Stalin [2].

The issue of blade design and selection related not only to the shape geometry, yet for aerodynamics and force analysis. In 2014, Vulloju, M.Kumar, E. Kumar, and K. Reddy introduced a direct approach for estimating the forces acting the blade induced from the solid to fluid flow interactions. [3]

Before the previous article with one month, another article published by M.R. Saber, M.H. Djavaraeshkian introducing the same concept the impact of blade design on the wind turbine performance. The analysis used genetic algorithm as optimization technique for the blade shape; optimum blade shape was E387 Eppler. A comparison was carried out between optimum shape and NERL phase VI cross section; the result from comparison a slight improvement in the power factor [4].

September 2012 Schubel and Crossley aroused the conflict of increasing performance while maintaining a structure that supports the loads; such comments give reason why we need approaches to select, design and optimize blades from material point of view [5]. 2012 Cai, Zhu, Pan, and Gu presented structural optimization using finite element analysis and Particle Swarm method for HWAT blade [6].

\section{Composite Materials}

Thousands years before calendar Pharaohs built tombs and templates using composites bricks; which consists of straw and mud. Another famous monumental used mud bricks is the Djenne mosque built in 1907 in Maali at West Africa [7]. There are many historical examples of composite materials using natural components.

Many researches started to develop before the period of 1950 has to study the behaviour of building using reinforced concrete. The concept of composition sand, cement, minerals rocks, and steel bar inspired many scientists. Stephen W. Tsai one of the most famous contributor to composite material science concerned by what affects composites and how they behave under different condition [8]. Since 1960's and Tsai was very devoted to study the behaviour of composite material, in the end, he could derive equations to formulate the behaviour based on classic elasticity.

Tsai model based on classic plastic model named after the great scientist Henry Tresca, the founder of plasticity science. Henry Tresca defined new criterion to describe the flow stress in the plastic region. Then it came to Timoshenko who developed failure criteria and introduced it in his publications and handbook Elasticity. In addition, Richard Von Misses developed another new criterion called von misses yield criteria in the early 1940's. [9]

For decades and scientists are concerned with updating elastic models to cope with new design trends. Professor John Reddy was one of the pioneers in introducing new models using finite elements and variation methods. In 2010 Reddy, Arcinieg and Moleiro published an article introducing a finite element analysis technique for composite plates and shells used in the aerospace [10]. 
Optimization of composite lamina is a rich research field, which related to different application. In 2007, Almeida and Awruch introduced a genetic algorithm optimization technique for composite plates and shells design, in which the decision variables are orientation angle and ply thickness [11]. In 2010, Almeida and Awruch implemented harmony search algorithm for rectangular composite laminate, the decision variable were ply thickness and fibre orientation [12]. Akbulut and Sonmez formulated a simulated annealing algorithm to optimize design procedure of laminated composites; the objective was reduction of thickness [13].

\section{Genetic algorithm}

Optimization model is a set of iteration to find optimum value for decision variables without violating the constraint parameter, in addition to maximizing or minimizing the objective function. There are different methods for solving the optimization model; those methods depend on the nature of the model. Thus, model categorized from the aspect of decision into variables nature, objective function behaviour, degree of constraints.

Optimization models are categorized according to the behaviour of the model such as (one dimension, multidimensional, linear, nonlinear, integer, mixed integer, continues, statics, dynamics, deterministic, and stochastic). The model could be a multidimensional, deterministic, and linear with integer decision variables having static behaviour. The identification of model type will facilitate the proper solving method such as graphical solution, exact solution, Dichotomous search, golden section, quadratic interpolation, cubic interpolation, Fibonacci search, Davis and Campeny, Newton, or steepest-descent).

The paper presents another direction for solving optimization model known as evolutionary method; it considered beneath artificial intelligence algorithms category. Genetic algorithm is an iterative search method depends on the fitness of each solution set to find the optimum results from whole problem domain. In early 60's a professor from university of Michigan named John Holland studied the development of genes behaviour in living organisms and he started to mimics or imitate such behaviour by a mathematical algorithm. The first publication for Professor John Holland was 'adoption in Natural and artificial systems' 1975. [14]

Genetic algorithm represents the problem in the form of chromosome that includes the property for each entity. Properties then translated to real values and evaluated for the aspect of objective function. Evaluated results used as guide to reproduce procedure to breed new generation that is more fit.

Genetic optimization algorithm consists of individual, and population. The solo solution called individual; on the other hand, a set of solution called population. Search technique followed by genetic algorithm starts with generating initial population, then breeding new modified population until satisfying the stopping criteria.

Individual consists of two elements genotype and phenotype. Chromosome is the form of genotype that is a raw representation for the solution variables. The way of expressing the value of solution called phenotype. The Chromosome consists of genotype array each one represent specific phenotype. Model presented herein consists of hundred twenty-three genotype forming one chromosome. There are several methods to represent each phenotype in genotype then join into single chromosome; such as, binary, hexadecimal, and octal encoding.

Breeding is the heart of any genetic algorithm. Breeding is the method to create a new generation from the previous population, imitating the biological behaving during reproduction of genes in living species. Four operators are carried out to accomplish the 
proper breeding process and to generate the new offspring. First operator is selection of parents, and then breeds those selected parents to generate offspring. Breeding starts with crossover, then mutation, tables ( 1 and 2 ) show the basic concept of crossover and mutation.

\section{Formulating the blade optimization model}

In order to choose the optimized criterion, an objective function defined in equation 1 . The aim of the objective function is to reduce the weight while maintaining acceptable strength behaviour. Therefore, the objective function depends on the minimization the value of polynomial failure criteria and the ratio of current weight to extreme weight

$\operatorname{Min} Z=$ Weight

The variables that affect the objective function's value called decision variables. Blade structure design consists of several design variables such as composite material: reinforcement material used in each layer, matrix material used in each layer, fibre volume fraction for each layer, and shape parameters: number of layers, thickness of each layer, width of core box, , and orientation of reinforcement in each layer. Consequently, the number of decision variables arrays is thirteen variable arrays. Table 3 summarizes the decision variables chosen for the presented model.

Constraints are determined according to the aspects of study. For example, there are limits, if the model selected maximum thickness for all layers and maximum number of layers, then those selections should not violate the geometric limitation, as shown in Table 4.

The chromosome presented in the form of bit string; Table 5 shows the number of bits representing each genotype. Total number of bits called chromosome length equal to 323 bytes. Consequently, solutions number equal to $2^{323}$ approximately $1.7 \times 10^{97}$ solutions.

The evaluation of a fitness function depends on the mechanical model presented in the subsequent section. Fitness function role is to sort individual in the population according to their objective value.

Reproduction process carried on three steps, as the following, selection, crossover, and mutation. Selection is a process to choose the fitted individuals from the population to generate offspring with higher fitness. There are two types of selection method. The first called proportional selection where selection for individuals carried regarding the fitness value relative to others values. The second method called ordinal-based selection, which selects upon ranks of individuals according to the fitness value. Consequently, selection depends on the value of fitness for each individual in the population according to the design of fitness function in the mathematical modelling and formation.

Crossover is a process of mixing selected individuals to generate new individuals with better fitness. The process carried through selection of a point where the crossing occurs after this point. Different methods used to select this point and redundancy of crossing point. Method selected to carry crossover depends on the nature of chromosome; whether it is haploid (each genotype has a single chromosome) or diploid (each genotype has a multi chromosome). The most common methods constraints depended system; in which the location of crossover point mix the same genotype with each other.

Stopping conditions depend on the desired outcome and computation device capabilities. Consequently, the condition could depend on number of iterations, a maximum number of generations after stalling, change in the tolerance of fitness function, or time of simulation. 


\section{Mechanical Model}

The presented model evaluates the design parameters generated by genetic algorithm against constant inputs from aerodynamic analysis. Consequently, first part will clarify variables introduced to the model and constant input data. The second part describes geometric relations, reference system, and shape parameters, and Input data from aerodynamic analysis.

Three reference frames defined for the blade such as global, centre, and aerodynamic frames. Global reference frame located at the tip of airfoil notated by O. Centre reference frame located at the centre of shape (GC). Aerodynamic reference frame located at aerodynamic centre (AC). Air loads resolved at the aerodynamic centre in the form of tangent, normal forces and moment couple shown in Fig. 2.

The cross-section geometry characteristics defined using the NACA 4-digit designation (NACA xxxx-xx). The two digits after the hyphen state the chord length. First digit after the letters indicates the maximum camber height as percentage of the chord length. Second digit indicates the location of maximum camber height as tenth digit representation. The two digits before the hyphen represent the maximum thickness ratio of chord length. The following equations describe the shape of airfoil in two dimensions. [1]

$y=\frac{t}{0.2}\left(a_{0}\left(\frac{x}{c}\right)^{0.5}+a_{1}\left(\frac{x}{c}\right)^{1}+a_{2}\left(\frac{x}{c}\right)^{2}+a_{3}\left(\frac{x}{c}\right)^{3}+a_{4}\left(\frac{x}{c}\right)^{4}\right)$

Where $\mathrm{a}_{0}=0.2969, \mathrm{a}_{1}=-0.126, \mathrm{a}_{2}=-0.3516, \mathrm{a}_{3}=0.2843, \mathrm{a}_{4}=-0.1036, \mathrm{t}=$ the maximum thickness and $\mathrm{c}=$ the chord length.

The following two equations represent the camber effect.

$b_{1}=\frac{b_{7}\left(2 b_{6} x-x^{2}\right)}{b_{6}{ }^{2}}$, if $x<b_{6}, b_{2}=\frac{b_{7}\left(\left(1-2 b_{6}\right)+2 b_{6} x-x^{2}\right)}{\left(1-b_{6}\right)^{2}}$, if $x \geq b_{6}$

Where $b_{6}$ is the camber location and $b_{7}$ is the camber percentage of chord length.

Then equations describing the upper and lower profile of the airfoil are as the following:

$$
\left(y_{u, l}\right)_{\text {head }}=b_{1} \pm y \text { and }\left(y_{u, l}\right)_{\text {tail }}=b_{2} \pm y \text { for all } x \text { domain }
$$

Centrifugal force acts at the centre of gravity; hence, the following two equations estimate the coordinates of this centre in reference to airfoil global frame.

$x_{g c}=c\left(\left(\frac{a_{0}}{2.5}+\frac{a_{1}}{3}+\frac{a_{2}}{4}+\frac{a_{3}}{5}+\frac{a_{4}}{6}\right) /\left(\frac{a_{0}}{1.5}+\frac{a_{1}}{2}+\frac{a_{2}}{3}+\frac{a_{3}}{4}+\frac{a_{4}}{5}\right)\right)$,

$y_{g c}=\frac{2}{A}\left(y_{1}+y_{2}-y_{3}\right), z_{g c}=\frac{\text { lenght }}{2}$

Where the $y_{1}, y_{2}$ and $y_{3}$ are the expression for surface integration for airfoil gradient equation.

Lift and drag forces act at centre of pressure. Distribution of pressure changes that cause the pressure centre to be variable. On the other hand, force analysis needs a fixed point for aerodynamic forces. Consequently, lift and drag forces are resolved into force and moment acting at fixed point called aerodynamic centre. Subsonic blade has aerodynamic centre located at $29 \%$ of chord length on symmetric axis. $y$ coordinate is determined by similarity between centre of shape coordinate and $x$ coordinate for aerodynamic centre; due to the inclination of symmetric line. [15]

$x_{a c}=0.29 * c, y_{a c}=\frac{\left(y_{g c^{*} x_{g c}}\right)}{x_{a c}}$ 
Blade weight depends on the total area of the cross section and density of material. Total area composite of shell and core cross section area. Shell area $\left(A_{s}\right)$ estimated by calculating difference between the integration of outer and inner profiles. The core area derived with the same method.

$$
\begin{aligned}
& A_{s}=\int_{0}^{b_{6}}\left(y_{u}\right)_{h} d x+\int_{b_{6}}^{b_{0}}\left(y_{u}\right)_{t} d x+\int_{b_{0}}^{c}\left(y_{u}\right)_{t} d x-\int_{0}^{b_{6}}\left(y_{l}\right)_{h} d x-\int_{b_{6}}^{c}\left(y_{l}\right)_{t} d x \\
& \boldsymbol{A}_{\boldsymbol{s}}=\boldsymbol{A}_{\mathbf{1}}+\boldsymbol{A}_{\mathbf{2}}-\boldsymbol{A}_{\mathbf{3}}-\boldsymbol{A}_{\mathbf{4}}=\frac{2 t}{\mathbf{0 . 2}}\left(\frac{a_{0}}{1.5 \sqrt{\boldsymbol{c}}} \boldsymbol{c}^{1.5}+\frac{a_{1}}{2 \boldsymbol{c}} \boldsymbol{c}^{2}+\frac{a_{2}}{3 \boldsymbol{c}^{2}} \boldsymbol{c}^{3}+\frac{a_{3}}{4 \boldsymbol{c}^{3}} \boldsymbol{c}^{\mathbf{4}}+\frac{\boldsymbol{a}_{4}}{5 \boldsymbol{c}^{4}} \boldsymbol{c}^{5}\right)
\end{aligned}
$$

For an ideal case, the composite volume is the summation of matrix and fibre volumes. Hence, the percentage of fibre volume to composite volume considered a key parameter to the design of composite laminate. The rule of mixtures predicts density, strength, and elastic modules as discussed in [16].

The rule of mixtures used to predict the engineering constants too. Although there are limitations on predicting the transverse constants, it shows acceptable results for predicting axial modulus of elasticity and rigidity only. Consequently, the prediction of transverse properties is completely deviated from the experimental data. There are different approaches and methods formulate relation for transverse properties. Halphin Semi-empirical formula for predicting the transverse properties of composite lamina that found in [17]. Another method called Tsai Hahn that is used in the analysis and found in [18] [19]. Prediction of material strength values carried out using the same technique used for material properties.

$\frac{1}{E_{2}}=\frac{1}{v_{f}+\eta_{2} v_{m}}\left[\frac{v_{f}}{E_{f}}+\frac{\eta_{2} v_{m}}{E_{m}}\right]$ where $\eta_{2}=1$

$\frac{1}{G_{12}}=\frac{1}{v_{f}+\eta_{2} v_{m}}\left[\frac{v_{f}}{G_{f}}+\frac{\eta_{2} v_{m}}{G_{m}}\right]$ where $\eta_{2}=0.5$

\section{Force analysis}

Blade loading condition include aerodynamic loads (Moment couple, tangent and normal force) and inertia load (centrifugal and weight). The air load is model inputs. They are resolved on the aerodynamic centre. Inertia loads acts at the mass centre in 3D study or centre of shape in $2 \mathrm{D}$ section study.

Blade mass $\left(\mathrm{M}_{\mathrm{T}}\right)$ calculated by summation mass of each lamina in shell and core. Centrifugal force $\left(\mathrm{F}_{\mathrm{c}}\right)$ depends on blade mass, rotation speed, and radius of wind turbine arms.

$$
F_{c}=M_{T} R \omega^{2}, M_{T}=\sum_{i=1}^{n o \text { of shell layers }} V_{s i} * \rho_{s i}+\sum_{j=1}^{n o \text { of core layers }} V_{c j} * \rho_{c j}
$$

Where $\mathrm{R}$ is the arm radius, $\omega$ is the angular speed, $M_{T}$ is the segment total mass, $V_{s i / c j}$ is the single shell/core lamina volume, $\rho_{s i / c j}$ is the density of single shell/core lamina.

The components of resultant force acting at the centre of gravity shown in equation

$$
F_{x}=F_{\text {tangent }}, F_{y}=F_{c}+F_{\text {normal }}, F_{z}=M_{T} * g
$$

Where $F_{x}$ is the $\mathrm{x}$-axis component, $F_{y}$ is the $y$-axis component, $F_{z}$ is the $z$-axis component, $F_{\text {tangent }}$ is the aerodynamic tangent component, $F_{n o r m a l}$ is the aerodynamic force normal component, and $\mathrm{g}$ is the gravity acceleration. The units of all the forces are Newton. 
The moment force around the three axes is shown in equation

$M_{z}=M_{\text {blade }}-F_{\text {tangent }}\left\|y_{c}-y_{a c}\right\|-F_{\text {normal }}\left\|x_{c}-x_{a c}\right\|+M_{\text {bending } F x \text { \& Fy }}+M_{\text {shear }}$

First term $\left(M_{\text {blade }}\right)$ indicates the torque applied on the blade due to air loads. The second and third terms are the moment applied due to equivalence of air load from aerodynamic centre to shape centre. Fourth term is the value of bending moment due to $\boldsymbol{F}_{\boldsymbol{x}}$ in the plane X-Z and $\boldsymbol{F}_{\boldsymbol{y}}$ in the plane y-z. Last term is the moment due to shear force acting at the centre of shear.

\section{Stress and failure analysis}

Starting step is blade idealization into two sections. The first section is the core, which carries all direct and torsion loads. Second section is the shell, which carries all shear loads. After that, all loads analyzed into forces per unit length for each section. Stress analysis carried using Classical Laminate theory presented in [1], where each section stiffness matrices consists of extensional stiffness, bending, and coupling coefficients. The material failure analysis is checked using Tsai Hill Failure criteria presented in [2]. The fitness function always equal design weight until failure occur in any lamina, then the model stop and fitness value is altered with maximum weight according to upper boundary.

\section{Case study solving}

Aerodynamic loads are a result of extensive fluid structure simulation. Hence, the data imported to the model verified by computational fluid dynamics simulation done by (Blue Power Consultation Company). Load data contains reading for tangent, normal and moment at each rotation degree shown in Table 6. Model parameters are blade length, rotation speed, and arm radius shown in Table 7 . The following tables show the input data.

Test data implementation carried out on MATLAB genetic optimization GUI tool. Population type was double vector. Size of population depends on chromosome length where it equal tenth time variables number. The reason behind population dependence of chromosome length is the presence of enough individuals for proper selection. Fitness scaling is Rank sorting. Selection method follows stochastic uniform distribution technique. Reproduction used multi point crossover with fraction of 0.8 , while mutation was constraints dependent. The mutation flips random number according to genotype number location. Genetic algorithm used simple technique without any parallel or migration algorithms. Stopping conditions varied between maximum number of generation and fitness function tolerances.

\section{Conclusion}

The presented approach evaluated different layup composite material to aid designer in selecting proper material structure for vertical wind turbine. Data in Table 8 shows no constraints violation. Fitness values is less than maximum weight, which means no failure occurred in any lamina. Presented results give blade designer a role model to start with. Numbers of lamina needed for shell and core estimated clearly. In addition to, thickness of each lamina and core width indicated to brief the internal structure's geometry. Moreover, selection of material, orientation, and mixing conditions indicated. This design schema improves the blade design process because sometime designer scope directed toward expensive solution.

Results show that reduction of weight is promising while maintaining no failure. However, the model needs integration with cost analysis model to be capable of comparing different type of material such as carbon and Kevlar. Further works could include modification in optimization model to be multi objective model. Indeed this modification will need reconsider 
mixed integer model into full binary model. Another issue is the integrations of vibration analysis. This integration requires more definition of laminate as finite element analysis. Eventually, the experimentation of different optimization results to verify the approach results.

\section{References}

1. Charles L. Ladson and Cuyler W. Brooks, Jr. Development of a Computer Program to Obtain Ordinates for NACA 4-digit, 4-digit Modified, 6-digit, and 16-series Airfoils. Washington D.C : NASA STI Facility, November, 1975.

2. Design of NACA 63215 Airfoil for a Wind Turbine. N.Manikandan, B.Stalin. 2013, IOSR Journal of Mechanical and Civil Engineering (IOSR-JMCE), pp. 18-26.

3. Design Fabrication of Flipping Blade Vertical Axis Wind Turbine. Sreedhar Vulloju, M. Suresh Kumar, E. Manoj Kumar, K.Krishna Reddy. 2, India : Inpressco International Press Corporation, Febrauary 01, 2014, International Journal of Current Engineering and Technology, Vol. 1, pp. 677-682. E-ISSN 2277-4106.

4. Comparison of Performance Base and Optimized Blade of Horizontal Axis Wind Turbine. M.R. Saber, M.H. Djavaraeshkian. 1, Iran : International Journal of Reneable Energy Research, 2014, Vol. 4. ISSN 1309-0127.

5. Review Wind Turbine Blade Design. Peter J. Schubel, Richard J. Crossley. 1, Nottingham : Energies, 2012, Vol. 5. ISSN 1996-1073.

6. Structure Optimization Design of Horziontal Axis Wind Turbine Blades using Particle Swarm Optimization Algorithm and Finite Element Method. Xin Cai, Jie Zhu, Pan Pan and Rongrong GU. s.1. : Energies, 2012, Vol. 5. ISSN 1996 - 1073.

7. Holy Ground: Mud, Materiality, and Meaning in the Djenne Mosque. Apotsos, Michelle. 1, New Jersy: The State university of New Jersy, 2011, The Rutgers Art Review, Vol. 27, pp. 2-12. 0194-049X.

8. Tsai, Stephen W. Structural Behavior of Composite Materials. California: Philco Corporation, 1964.

9. Timoshenko, Stephen P. History of Strength of Materials. s.1. : McGraw-Hill, 1953.

10. Finite Element Analysis of Composite Plates and Shells. J.N. Reddy, Roman A. Arciniega, and Filipa Moleiro. s.l. : John Wiley and Sons (Encyclopedia of Aerospace Engineering), 2010. ISBN 978-0-470-68665-2.

11. Optimization of Composite Plates and Shells using a Genetic Algorithm and the Finite Element Method. s.1. : Asociacion Argentina de Mecanica Computacional, 2007, Vol. XXVI.

12. Optimization of Laminated Composite Structures using Harmony Search Algorithm. Awruch, Felipe Schaedle de Almeida and Armando Miguel. s.l. : Asociacion Argentina de Mecanica Computacional, 2010, Vol. XXIX.

13. Design Optimization of Laminated Composites using a new varient of Simulated Annealing. Mustafa Akbulut, Fazil O. Sonmez. s.l. : El Sevier - Computer and Structures, 2011, Vol. 89.

14. S.N.Sivanandam, S.N.Deepa. Introduction to Genetic Algorithm. s.1. : Springer, 2008.

15. E.L Houghton, P.W. Carpenter, Steven H. Collicott, Daniel T. Valentine. Aerodynamics for Engineering Students. s.l. : Butterworth-Heinemann, 2013.

16. Kaw, Autar K. Mechanics of Composite materials . s.1. : CRC Taylor and Francis, 2006.

17. Halphin, J. C. Effect of Enviromental Factors on Compoiste Materials. Ohio : Air Force Materials Laboratory, 1969. AFML TR 67423.

18. Gibson, Ronald F. Principles of Compoiste Material. s.1. : McGraw Hill, 1994.

19. Reddy, O.O. Ochoa and J. N. Finite Element Analysis of Composite Laminate. s.1. : Kluwer Academic Publishers, 1992. 


\section{Figures}

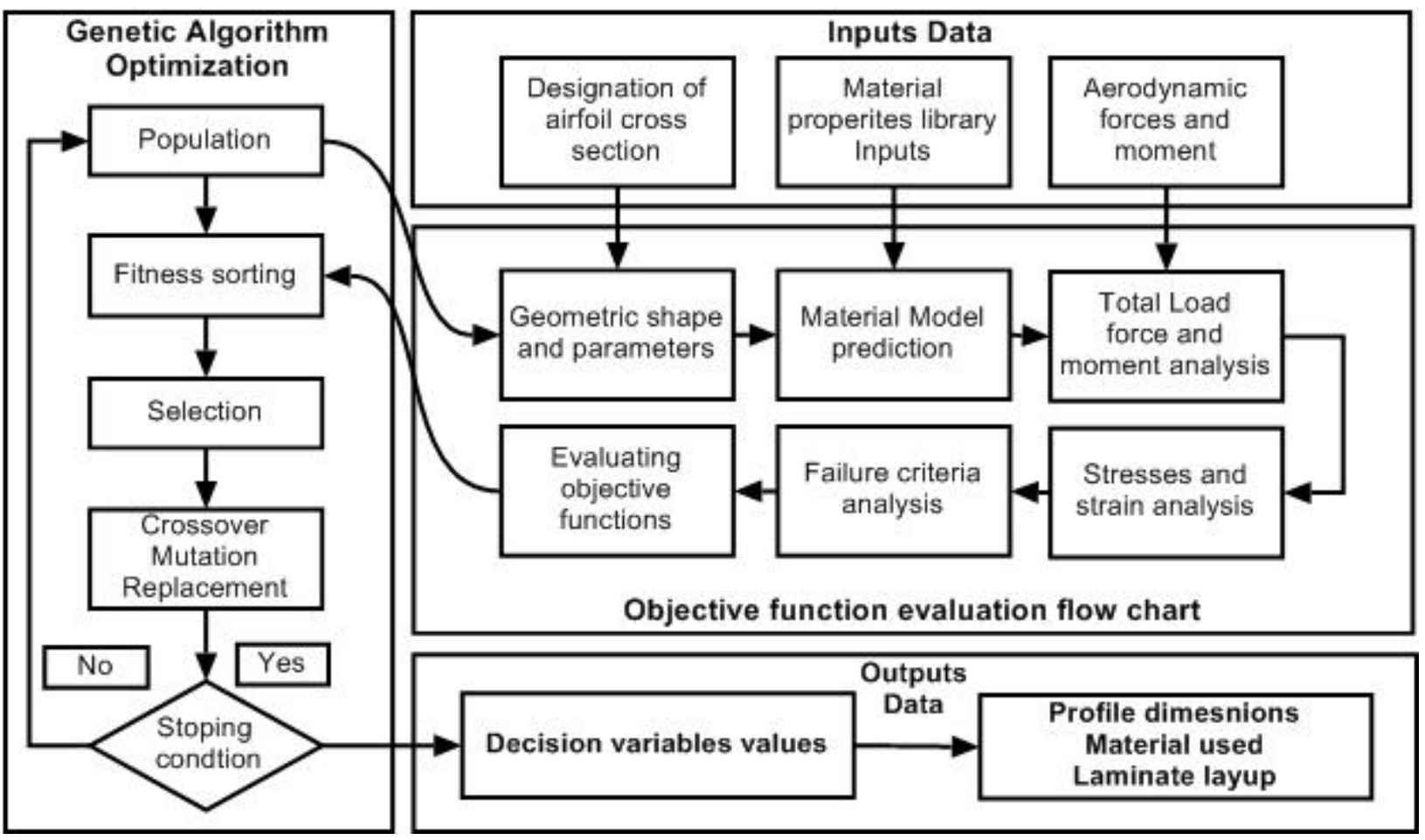

Fig. 1 Flow Diagram showing different steps for the Design and optimization approach

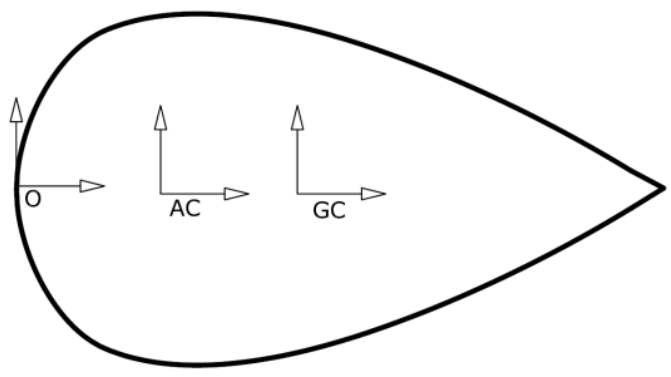

Fig. 2 shows the origin, aerodynamic center and centroid

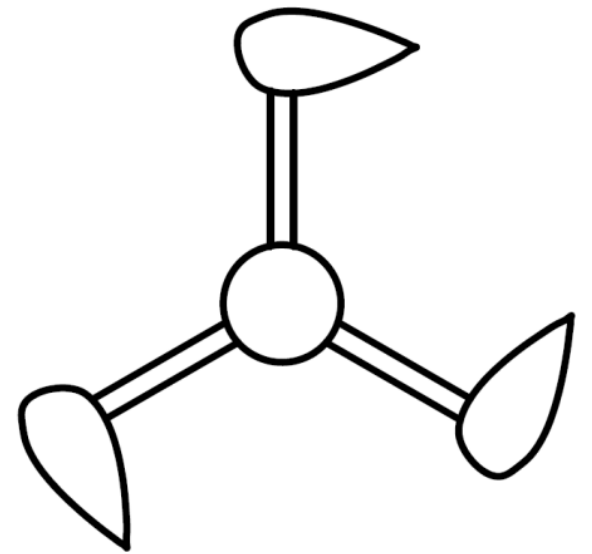

Fig. 3 Three blades vertical wind turbine (top view) 

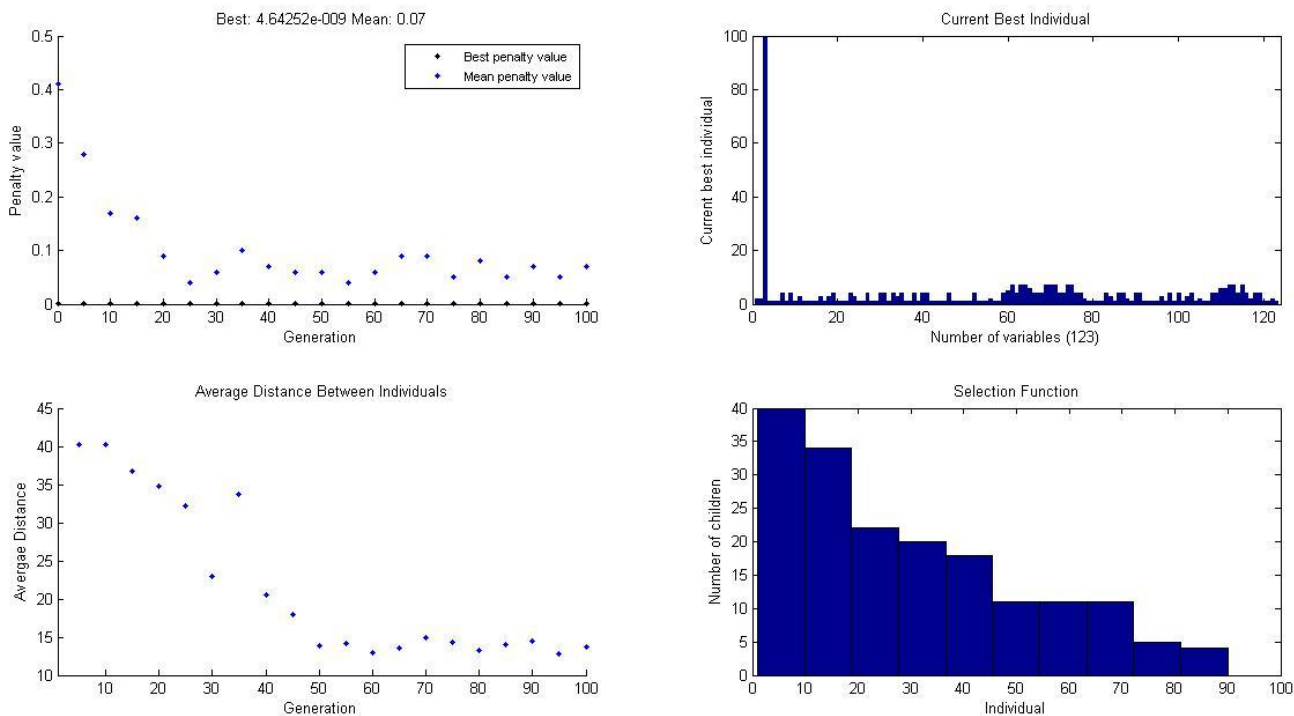

Fig. 4 Final Results of Genetic Algorithm showing all the random trends

\section{Tables}

Table 1 Crossover Explanation Example

\begin{tabular}{c|c|c|c}
\hline Individual & Before & After & Different Crossover mode \\
\hline $\mathbf{C}$ & 11001011 & $1100 \mid 0101$ & $\begin{array}{c}\text { Single point after 4 digits from the start the } \\
\text { crossover between C and B }\end{array}$ \\
\hline B & 10110101 & $10|00| 01 \mid 11$ & $\begin{array}{c}\text { Double point after 2 digits sequence the } \\
\text { crossover between C and B }\end{array}$ \\
\hline D & 00011100 & Rejected & \\
\hline A & 01100010 & Rejected & \\
\hline \hline
\end{tabular}

Table 2 Mutation Explanation Example

\begin{tabular}{c|c|c|c}
\hline \hline Individual & Before & After & Different Mutation mode \\
\hline C & 11001011 & 11011011 & $\begin{array}{c}\text { Single point flip the } 4^{\text {th }} \text { digit from the } \\
\text { start }\end{array}$ \\
\hline B & 10110101 & 10010001 & Double points flip $3^{\text {td }}$ digit and $6^{\text {th }}$ digit \\
\hline C' & 11000101 & 10010000 & Multi points $2^{\text {nd }}, 4^{\text {th }}, 6^{\text {th }}$, and $8^{\text {th }}$ \\
\hline B' & 10000111 & 11000011 & With ratio $20 \%$, and $75 \%$ \\
\hline
\end{tabular}


Table 3 Decision Variables notation

\begin{tabular}{|c|c|c|c|}
\hline No & Description & Notation & Nature \\
\hline 1 & Number of Shell Lamina & $\mathrm{X}(1)$ & Discreet \\
\hline 2 & Number of core Lamina & $\mathrm{X}(2)$ & Discreet \\
\hline 3 & Width of core box & $\mathrm{X}(3)$ & Continues \\
\hline 4 & Thickness of each shell lamina & $\mathrm{X}(4)-\mathrm{X}(19)$ & Continues \\
\hline 5 & Thickness of each core lamina & $X(20)-X(27)$ & Continues \\
\hline 6 & Fiber Material Index for each shell lamina & $\mathrm{X}(28)-\mathrm{X}(43)$ & Integer \\
\hline 7 & Matrix Material Index for each shell lamina & $\mathrm{X}(44)-\mathrm{X}(59)$ & Integer \\
\hline 8 & Fiber Volume Fraction for each shell lamina & $\mathrm{X}(60)-\mathrm{X}(75)$ & Continues \\
\hline 9 & Fiber orientation Index for each shell lamina & $\mathrm{X}(76)-\mathrm{X}(91)$ & Integer \\
\hline 10 & Fiber Material Index for each core lamina & $\mathrm{X}(92)-\mathrm{X}(99)$ & Integer \\
\hline 11 & Matrix Material Index for each core lamina & $X(100)-X(107)$ & Integer \\
\hline 12 & Fiber Volume Fraction for each core lamina & $\mathrm{X}(108)-\mathrm{X}(115)$ & Continues \\
\hline \multirow[t]{2}{*}{13} & Fiber orientation Index for each core lamina & $\mathrm{X}(116)-\mathrm{X}(123)$ & Integer \\
\hline & Total Number of independent variables & $\begin{array}{c}123 \\
X(1)-X(123)\end{array}$ & $\begin{array}{l}\text { Mixed } \\
\text { Integer }\end{array}$ \\
\hline
\end{tabular}

Table 4 Constraints and decision variables

\begin{tabular}{|c|c|c|c|c|}
\hline No & variable & Nature & Constraints & Units \\
\hline 1 & $\mathrm{X}(1)$ & Discreet & $2 \leq X(1) \leq 18$ & Index \\
\hline 2 & $\mathrm{X}(2)$ & Discreet & $2 \leq X(2) \leq 10$ & Index \\
\hline 3 & $\mathrm{X}(3)$ & Continues & $20 \leq \mathrm{X}(3) \leq 320$ & $\mathrm{Mm}$ \\
\hline 4 & $X(4)-X(19)$ & Continues & $1 \leq X(4)-X(19) \leq 3.20$ & $\mathrm{Mm}$ \\
\hline 5 & $X(20)-X(27)$ & Continues & $1 \leq X(20)-X(27) \leq 3.20$ & $\mathrm{Mm}$ \\
\hline 6 & $\mathrm{X}(28)-\mathrm{X}(43)$ & Integer & $1 \leq \mathrm{X}(28)-\mathrm{X}(43) \leq 4$ & Index \\
\hline 7 & $\mathrm{X}(44)-\mathrm{X}(59)$ & Integer & $1 \leq X(44)-X(91) \leq 4$ & Index \\
\hline 8 & $\mathrm{X}(60)-\mathrm{X}(75)$ & Integer & $1 \leq X(60)-X(75) \leq 9$ & Ratio \\
\hline 9 & $\mathrm{X}(76)-\mathrm{X}(91)$ & Integer & $1 \leq X(76)-X(91) \leq 4$ & Index \\
\hline 10 & $\mathrm{X}(92)-\mathrm{X}(99)$ & Integer & $1 \leq X(92)-X(99) \leq 4$ & Index \\
\hline 11 & $\begin{array}{c}X(100)- \\
X(107)\end{array}$ & Integer & $1 \leq X(100)-X(107) \leq 4$ & Index \\
\hline 12 & $\begin{array}{c}X(108)- \\
X(115)\end{array}$ & Continues & $1 \leq X(108)-X(115) \leq 9$ & Ratio \\
\hline 13 & $\begin{array}{c}X(116)- \\
X(123) \\
\end{array}$ & Integer & $1 \leq X(116)-X(123) \leq 4$ & Index \\
\hline
\end{tabular}


Table 5 Example on representation used in blade model

\begin{tabular}{c|c|c|c|c|c|c|c|c|c|c|c|c|c|c|c}
\hline \hline genotype & 1 & 2 & 3 & 4 & 5 & 6 & 7 & 8 & 9 & 10 & 11 & 12 & 13 & 14 & 15 \\
\hline Bit size & 4 & 3 & 4 & 4 & 4 & 4 & 4 & 4 & 4 & 4 & 4 & 4 & 4 & 4 & 4 \\
\hline genotype & 16 & 17 & 18 & 19 & 20 & 21 & 22 & 23 & 24 & 25 & 26 & 27 & 28 & 29 & 30 \\
\hline Bit size & 4 & 4 & 4 & 4 & 4 & 4 & 4 & 4 & 4 & 4 & 4 & 4 & 2 & 2 & 2 \\
\hline genotype & 31 & 32 & 33 & 34 & 35 & 36 & 37 & 38 & 39 & 40 & 41 & 42 & 43 & 44 & 45 \\
\hline Bit size & 2 & 2 & 2 & 2 & 2 & 2 & 2 & 2 & 2 & 2 & 2 & 2 & 2 & 2 & 2 \\
\hline genotype & 46 & 47 & 48 & 49 & 50 & 51 & 52 & 53 & 54 & 55 & 56 & 57 & 58 & 59 & 60 \\
\hline Bit size & 2 & 2 & 2 & 2 & 2 & 2 & 2 & 2 & 2 & 2 & 2 & 2 & 2 & 2 & 3 \\
\hline genotype & 61 & 62 & 63 & 64 & 65 & 66 & 67 & 68 & 69 & 70 & 71 & 72 & 73 & 74 & 75 \\
\hline Bit size & 3 & 3 & 3 & 3 & 3 & 3 & 3 & 3 & 3 & 3 & 3 & 3 & 3 & 3 & 3 \\
\hline genotype & 76 & 77 & 78 & 79 & 80 & 81 & 82 & 83 & 84 & 85 & 86 & 87 & 88 & 89 & 90 \\
\hline Bit size & 2 & 2 & 2 & 2 & 2 & 2 & 2 & 2 & 2 & 2 & 2 & 2 & 2 & 2 & 2 \\
\hline genotype & 91 & 92 & 93 & 94 & 95 & 96 & 97 & 98 & 99 & 100 & 101 & 102 & 103 & 104 & 105 \\
\hline Bit size & 2 & 2 & 2 & 2 & 2 & 2 & 2 & 2 & 2 & 2 & 2 & 2 & 2 & 2 & 2 \\
\hline genotype & 106 & 107 & 108 & 109 & 110 & 111 & 112 & 113 & 114 & 115 & 116 & 117 & 118 & 119 & 120 \\
\hline Bit size & 2 & 2 & 2 & 2 & 2 & 2 & 2 & 2 & 2 & 2 & 2 & 2 & 2 & 2 & 2 \\
\hline genotype & 121 & 122 & 123 & & & & & & & & & & & & \\
\hline Bit size & 2 & 2 & 2 & & & & & & & & & & & & \\
\hline \hline
\end{tabular}

Table 6 Sample of Force input data

\begin{tabular}{c|c|c|c}
\hline \hline Degree & Moment Couple & Normal Force & Tangent Force \\
\hline 0 & 14.92344 & 122.8725 & 378.1605 \\
\hline 2.4 & -14.8822 & 130.0449 & 384.2296 \\
\hline 4.8 & -35.7909 & 144.6563 & 390.4343 \\
\hline 7.2 & -45.6371 & 159.0719 & 394.1597 \\
\hline 9.6 & -58.7571 & 173.7291 & 396.7187 \\
\hline 12 & -65.1742 & 186.647 & 395.0094 \\
\hline 14.4 & -62.2403 & 198.7465 & 391.186 \\
\hline 16.8 & -60.2535 & 210.8567 & 386.9634 \\
\hline 19.2 & -54.6376 & 220.2604 & 378.7905 \\
\hline 21.6 & -46.511 & 228.5552 & 369.6851 \\
\hline \hline
\end{tabular}

Table 7 Blade operating parameters

\begin{tabular}{c|c}
\hline Parameters & Value \\
\hline Rotation Speed & $100 \mathrm{RPM}$ \\
\hline Blade length & $18 \mathrm{~m}$ \\
\hline Segment Length & $6 \mathrm{~m}$ \\
\hline Method of fixation & Built in both end \\
\hline Arm Radius & $6 \mathrm{~m}$ \\
\hline Airfoil Designation & NACA 4971 \\
\hline Chord length & $0.750 \mathrm{~m}$ \\
\hline \hline
\end{tabular}


Table 8 Optimization Run 1 final value

\begin{tabular}{c|l|c}
\hline \hline No & Description & Value \\
\hline 1 & Number of Shell Lamina & 2 \\
\hline 2 & Number of core Lamina & 2 \\
\hline 3 & Width of core box & $100 \mathrm{~mm}$ \\
\hline 4 & $\begin{array}{l}\text { Thickness of each shell } \\
\text { lamina }\end{array}$ & {$\left[\begin{array}{ll}1 & 4\end{array}\right]$} \\
\hline 5 & $\begin{array}{l}\text { Thickness of each core } \\
\text { lamina }\end{array}$ & {$\left[\begin{array}{ll}4 & 1\end{array}\right]$} \\
\hline 6 & $\begin{array}{l}\text { Fiber Material Index for } \\
\text { each shell lamina }\end{array}$ & {$\left[\begin{array}{ll}4 & 2\end{array}\right]$} \\
\hline 7 & $\begin{array}{l}\text { Matrix Material Index for } \\
\text { each shell lamina }\end{array}$ & {$\left[\begin{array}{ll}3 & 2\end{array}\right]$} \\
\hline 8 & $\begin{array}{l}\text { Fiber Volume Fraction for } \\
\text { each shell lamina }\end{array}$ & {$\left[\begin{array}{ll}6 & 7\end{array}\right]$} \\
\hline 9 & $\begin{array}{l}\text { Fiber orientation Index for } \\
\text { each shell lamina }\end{array}$ & {$[2$} \\
\hline 10 & $\begin{array}{l}\text { Fiber Material Index for } \\
\text { each core lamina }\end{array}$ \\
\hline 11 & $\begin{array}{l}\text { Matrix Material Index for } \\
\text { each core lamina }\end{array}$ & {$\left[\begin{array}{ll}3 & 3\end{array}\right]$} \\
\hline 12 & $\begin{array}{l}\text { Fiber Volume Fraction for } \\
\text { each core lamina }\end{array}$ & {$\left[\begin{array}{ll}3 & 3\end{array}\right]$} \\
\hline 13 & $\begin{array}{l}\text { Fiber orientation Index for } \\
\text { each core lamina }\end{array}$ & {$\left[\begin{array}{ll}5 & 7\end{array}\right]$} \\
\hline \hline
\end{tabular}

